\title{
Anne Vo and Christina A. Christie (Eds.). (2015). Evaluation Use and Decision Making in Society: A Tribute to Marvin C. Alkin. Charlotte, NC: Information Age Publishing. Paperback, 190 pages. (ISBN: 978-1-68123-004-7)
}

\section{Reviewed by Margaret Schultz Patel, University of Denver/ Schultz Patel Evaluation}

Compared to other branches of research, the field of evaluation is uniquely concerned with producing actionable information. Without this charge, it is not clear what would distinguish evaluation from other types of applied research. Despite this seemingly simple focus, seasoned evaluators know all too well that there are often many barriers to shepherding evaluations toward achieving this final purpose. The volume under review contains the musings of seasoned evaluators and evaluation theorists grappling with these barriers from many different perspectives.

This book, which is the result of a symposium dedicated to celebrating the career of evaluation theorist Marvin C. Alkin, is a compilation of meditations about evaluation use from various scholars and thought leaders in the field. Evaluation use can be defined as the extent to which evaluation findings are used to inform practice and policy. These reflections are based primarily on the authors' lived experience as evaluators and evaluation theorists. One thing that becomes clear early on is that what we know about evaluation use-empirically speaking-is pretty paltry. Considering the youth of evaluation as a field, as well as the challenge of consistently operationalizing a latent construct such as use, this is not surprising.

To frame the subsequent discussion of evaluation use and decision making, the book begins with a clear discussion of the related historical context by Christina Christie, who reminds us that "evaluation grew out of the need to better understand the impact of U.S. federal policies" (p. 1). An allegory of how to facilitate decision making with soundly reasoned evaluation by Ernie House provides a tangible example for readers. A convincing argument that evaluations informed by strong evaluation theory are more likely to be used for decision making and why-hint: it has to do with the strength of evidence generated by theory-informed evaluation-is subsequently articulated by Stewart Donaldson and Tarek Azzam.

Next, Eric Barela shares his experiences as an internal evaluator grappling with the various tensions in balancing rigor with relevance and compliance with 
learning. Barela integrates Volkov's (2011) conceptual framework of tensions inherent to the role of the internal evaluator with the well-known taxonomy of evaluation theories (Alkin \& House, 1992). This application of an important theoretical framework to a pragmatic assessment of the roles internal evaluators play felt to this reader like a rallying cry-there is a way to meaningfully grapple with the tensions experienced as an internal evaluator, and trying to bulldoze your colleagues with a one-size-fits-all approach is not the best way to encourage evaluation use. When compared with their external counterparts, internal evaluators are arguably best positioned to influence an organization to use evaluation to guide decision making over the long term, and this chapter will serve as an invaluable decision tree for those grappling with how to do so.

Richard Nunneley, Jean King, Kelli Johnson, and Laura Pejsa contribute a literature review of the empirical evaluation literature on "how use and influence affect decision making" (p. 55). In an elegantly argued and largely philosophical piece, they demonstrate how little we actually know about these processes and raise a call for more direct assessments of this question, as "rigorous study, theory development, theory testing, and healthy debate around theory are not simply learning exercises, but an investment in our field and its potential impact on our society" (p. 68). Eleanor Chelimksy, a long-time government evaluator, shares her experiences from the field related to barriers to evaluation use in that context. These hard-earned lessons, such as understanding when an evaluation has been commissioned for purely symbolic reasons, should be considered by proactive evaluators working to get ahead of the curve on barriers to evaluation use. The next two articles argue convincingly for the importance of incorporating additional perspectives into efforts to ensure evaluation use: accountability and learning through a transformative lens (J. Bradley Cousins, Katherine Hay, and Jill Chouinard) and culturally responsive decisions in evaluation practice (Wanda Casillas, Rodney Hopson, and Ricardo Gómez). Both chapters contain important practical guidance that is useful for helping the field move beyond the same old challenges that seem to hamper evaluation use. Michael Quinn Patton, pioneer of utilization-focused evaluation, then explicates a convincingly argued diatribe on what may lead to evaluations being misused (hint: poorlydone evaluations factor prominently, though incompetence is one of the more innocuous drivers of misuse in Patton's estimation). Editor Anne Vo concludes the volume with a helpful synthesis of what was learned and what is needed to drive the field forward.

This book is a great read when one is in need of some refocusing or revving up one's passion for evaluation. This book will be a treat for workaday practitioners trapped in the relentless cycle of responding to Requests for Proposals (RFPs), tempering client expectations, or paring down their own evaluative aspirations. Perhaps more importantly, this volume picks up a conversation in the literature about how good evaluation is at achieving what many would consider its core mission: influencing decision making. This is an idea that should be of supreme importance to all evaluation practitioners and academic researchers of evaluation. 
This volume highlights many ways to think about use and how to combat lack of use or misuse. As a whole, it does a great job summarizing what we know, empirically and anecdotally, about evaluation use. Beyond this, the volume also contains a charge to get better at delivering relevant and actionable evaluation findings. This book is an important contribution to a field still trying to define itself and realize its potential.

\section{REFERENCES}

Alkin, M., \& House, E. (1992). Evaluation of programs. In M. Alkin (Ed.), Encyclopedia of educational research (6th ed., pp. 462-467). New York, NY: Macmillan.

Volkov, B. B. (2011). Beyond being an evaluator: The multiplicity of roles of the internal evaluator. In B. B. Volkov \& M. E. Baron (Eds.), Internal evaluation in the 21st century. New Directions for Evaluation, 132, 25-42. 